\title{
HUBUNGAN TUNTUTAN PEKERJAAN TERHADAP KEJADIAN STRES KERJA PADA JURNALIS PEREMPUAN DI KOTA PALEMBANG
}

\author{
Mesi Parlinda $^{1)}$, Tan Malaka ${ }^{2)}$, Novrikasari $^{1)}$ \\ ${ }^{1}$ Fakultas Kesehatan Masyarakat Universitas Sriwijaya \\ ${ }^{2}$ Fakultas Kedokteran Universitas Sriwijaya \\ E-mail: mesi_echy80@yahoo.com
}

\begin{abstract}
Problems:Female journalists are very at risk of experiencing work stress due to the arduous and risky task of gathering information to make a story. Profession as a journalist who is always chased by deadlines and high mobility can cause stress. The Aim of The Research:This study aims to analyze the risk factors for job stress in female journalists in Palembang City. Research Method:The study used a cross-sectional design involving 85 female journalists in Palembang City who were randomly selected from March to June 2020. The data was collected through a Health Safety Executive (HSE) Management Standard Indicator Tools questionnaire as well as interviews and direct observation by psychologists. The Results: The analysis showed that there were 4 female journalists who experienced work stress (4.7\%). The risk factor that affects job stress is job demands pvalue $=0.005($ OR $0.833 ; 95 \%$ CI $0.697-0.997)$. From the results of interviews and direct observation by psychologists, it was found that all four respondents experienced a tendency for light work stress. Conclusions:The risk factors that most influence the incidence of job stress for female journalists in Palembang City are job demands and personality types. Age, marital status, number of children, length of work, years of service, desk coverage, control of work, social support, interpersonal relationships, roles and changes in the organization have no effect on job stress.
\end{abstract}

Keywords: Job stress, Occupational stress, Female journalist

\begin{abstract}
ABSTRAK
Permasalahan:Jurnalis perempuan sangat berisiko mengalami stres kerja karena tugas yang berat dan berisiko dalam mengumpulkan informasi untuk membuat sebuah berita. Profesi sebagai jurnalis yang selalu dikejar deadline dan mobilitas tinggi dapat menimbulkan stres. Tujuan Penelitian:Penelitian bertujuan menganalisis faktor risiko stres kerja pada jurnalis perempuan di Kota Palembang.Metode Penelitian:Penelitian menggunakan desain cross sectional dengan melibatkan 85 jurnalis perempuan di Kota Palembang yang dipilih secara acak dari Maret hingga Juni 2020. Pengumpulan data dilakukan melalui kuesioner Health Safety Executive (HSE) Management Standart Indicator Tools serta wawancara dan observasi langsung oleh psikolog. Hasil: Hasil analisis menunjukkan jurnalis perempuan yang mengalami stres kerja sebanyak 4 orang $(4,7 \%)$. Faktor risiko yang berpengaruh terhadap stres kerja adalah tuntutan pekerjaan $p$-value $=0,005$ (OR 0,$833 ; 95 \%$ CI 0,697 - 0,997). Dari hasil wawancara dan observasi langsung oleh psikolog didapatkan keempat responden mengalami kecenderungan stres kerja ringan.Kesimpulan:Faktor risiko yang paling berpengaruh terhadap kejadian stress kerja pada jurnalis perempuan di Kota Palembang adalah tuntutan pekerjaan dan tipe kepribadian. Sedangkan usia, status pernikahan, jumlah anak, lama kerja, masa kerja, desk liputan, kontrol terhadap pekerjaan, dukungan sosial, hubungan interpersonal, peran dan perubahan dalam organisasi tidak memiliki pengaruh terhadap stres kerja.
\end{abstract}

Kata Kunci:: Jurnalis perempuan, Stres kerja, Wartawan 


\section{PENDAHULUAN}

Stres kerja didefinisikan sebagai respon fisik dan emosional berbahaya, yang terjadi ketika pekerjaan tidak sesuai dengan kemampuan, sumber daya, atau kebutuhan pekerja. Stres kerja dapat menyebabkan kesehatan yang buruk dan bahkan cidera (NIOSH, 2001). Dalam pelaksanaan higiene industri, hazard psikososial yang berhubungan dengan stres kerja merupakan salah satu masalah yang tidak boleh dianggap ringan.

Di beberapa negara kasus yang berkaitan dengan potensi bahaya psikososial stres kerja bahkan cukup dominan. Sebagai gambaran, hasil penelitian menyimpulkan, satu dari tiga orang tenaga kerja di Eropa, atau lebih dari 40 juta orang dilaporkan mengalami stres kerja (EU-OSHA, 2002).Hasil riset yang berhubungan dengan kondisi kerja di Eropa menggambarkan, pada tahun 2005 sekitar 20\% dari tenaga kerja yang tergabung dalam 15 perserikatan buruh dan 30\% dari anggota baru menyatakan, gangguan kesehatan yang mereka alami adalah dampak dari stres kerja (Parent-Thirion et al., 2007).

Data terbaru Labour Force Survey (LSC) yang dirilis Health Safety Executive (HSE) menunjukkan, selama periode 2018/2019 terdapat 602.000 kasus stres terkait pekerjaan, depresi atau kecemasan, dengan tingkat prevalensi 1.800 per 100.000 pekerja.(HSE, 2019)Angka ini meningkat dibanding periode sebelumnya 2017/2018 dimana jumlah kasus stres terkait pekerjaan, depresi dan kecemasan sebanyak 595.000 kasus, dengan tingkat prevalensi yang hampir sama (Health and Safety Executve, HSE and Health and Safety Executve, 2017).

Menurut National Safety Council (1994) ada sepuluh profesi yang rentan stres, satu diantaranya adalah jurnalis atau reporter. Sembilan lainnya yaitu petugas pemadam kebakaran, perawat, pilot, guru, petugas paramedis, pegawai pos, petugas customer service dan pelayanan, manajer tingkat menengah dan sekretaris (Pratama, 2012).

Hasil penelitian mengungkapkan, dukungan organisasi memoderasi hubungan antara tugas yang diemban seorang jurnalis dan stres kerja.Penelitian yang melibatkan 127 jurnalis Yordania sebagai responden ini menyoroti kondisi jurnalis yang membuat berita dengan topik sensitif serta berada di daerah konflik. Pada kondisi tersebut, jurnalis membutuhkan dukungan tambahan dari manajemen perusahaan surat kabar untuk mengurangi stres kerja yang tinggi, serta memotivasi mereka untuk menghasilkan pekerjaan yang berkualitas (Muala, 2017).

Data peningkatan kematian tak terduga terjadi pada pekerja media Tiongkok dari 2011 hingga 2015. Pada 28 April 2014 hingga 27 Mei 2014 terdapat enam pekerja media Tiongkok yang sebagian besar merupakan eksekutif senior, bunuh diri karena tekanan terkait 
pekerjaan. Usia rata-rata mereka adalah 44 tahun. Investigasi lebih lanjut menemukan bahwa kematian pekerja media secara resmi yang dilaporkan sebagai akibat dari bunuh diri atau penyakit akut selama tahun 2014 berjumlah lebih dari 17. Angka ini meningkat dari tahun 2011 dimana hanya ada tujuh kasus bunuh diri, delapan kasus pada 2012 dan 11 kasus pada 2013, pada usia rata-rata lebih muda dari 45 tahun (Wang and Jiang, 2016).Penelitian tersebut juga mengungkapkan, kejadian terakhir dimana sembilan kematian tak terduga pada pekerja media di usia rata-rata 39 tahun dalam 60 hari dari Mei hingga Juni 2016 menjadi masalah sosial yang membutuhkan perhatian khusus dari para peneliti dan praktisi. Penelitian tersebut menyimpulkan dua faktor penting yang berkontribusi terhadap bunuh diri yaitu stres terkait pekerjaan dan transformasi media di era teknologi digital.

Dalam sebuah survei, sekitar $60 \%$ perempuan yang bekerja menyebut stres sebagai masalah nomor satu mereka di tempat kerja. Selain itu, tingkat penyakit yang berhubungan dengan stres hampir dua kali lebih tinggi untuk wanita daripada pria (Balhara, Verma and Gupta, 2012)Jurnalis perempuan yang telah menikah dan bekerja adalah seorang wanita dengan peran ganda. Peran ganda adalah dua peran atau lebih yang dijalankan dalam waktu yang bersamaan (Soeroso, 2008).Berdasarkan studi pendahuluan yang penulis lakukan, tugas jurnalis perempuan cukup berat dan berisiko tinggi dalam memburu berita.Tidak hanya faktor keselamatan, jurnalis perempuan juga kerap menghadapi dampak dari pemberitaan yang kadangkala tidak disukai oleh narasumber maupun pihak yang terkait. Hal ini menimbulkan ancaman tersendiri bagi keselamatan wartawan (Luviana, 2012).

Sepanjang penelusuran peneliti, di Indonesia belum pernah ada peneltian yang khusus meneliti faktor risiko stres kerja pada jurnalis perempuan. Penelitian tentang faktor risiko stres kerja pada jurnalis perempuan di Kota Palembang perlu dilakukan untuk mengetahui faktor-faktor risiko penyebab terjadinya stres kerja pada jurnalis perempuan di Kota Palembang, supaya dapat diketahui cara mengendalikannya agar tidak memberikan pengaruh negatif pada produktivitas jurnalis dan target perusahaan.

\section{METODE PENELITIAN}

Metode yang digunakan dalam penelitian ini adalah metode kuantitatif dengan rancangan cross sectional. Sampel penelitian adalah 85 orang jurnalis perempuan yang dipilih secara acak, dari media cetak dan online di Kota Palembang yang sudah diverifikasi oleh Dewan Pers dan telah mengikuti ujian kompetensi wartawan. Faktor risiko yang diteliti adalah demografi individu (usia, status pernikahan, jumlah anak, lama bekerja dalam seminggu, masa kerja dan desk liputan) dan job stressors (tuntutan pekerjaan, kontrol 
terhadap pekerjaan, dukungan sosial di tempat kerja, hubungan interpersonal, peran dan perubahan dalam organisasi).

Penelitian dilakukan dalam dua tahap. Tahap pertama, data yang dikumpulkan adalah faktor risiko stres dan tingkat stres yang terjadi pada responden dengan alat ukur berupa kuesioner. Kuesioner yang digunakan dalam penelitian ini adalah kuesioner Health Safety Executive (HSE) Management Standart Indicator Tools. Kuesioner ini adalah kuesioner baku yang sudah teruji validitas dan reliabilitasnya.Tahap kedua, data dikumpulkan melalui wawancara dan observasi langsung oleh psikolog. Setelah semua data dianalisis, pada tahap akhir dilakukan interpretasi secara keseluruhan dari kedua analisis yang telah dilakukan.

\section{HASIL}

\section{Analisis Univariat}

Tabel 1. Distribusi Frekuensi Demografi Individu Responden

\begin{tabular}{lcc}
\hline Variabel & $\mathbf{N}$ & $\mathbf{\%}$ \\
\hline Usia & & $20 \%$ \\
$\quad \leq 35$ tahun & 17 & $80 \%$ \\
$>35$ tahun & 68 & \\
$\begin{array}{l}\text { Status Pernikahan } \\
\quad \text { Belum menikah }\end{array}$ & 38 & $44,7 \%$ \\
$\quad$ Menikah & 47 & $55,3 \%$ \\
Jumlah Anak & & \\
$\quad \leq 2$ orang & 75 & $88,2 \%$ \\
$>\quad$ orang & 10 & $11,8 \%$ \\
Lama Kerja (Jam/Minggu) & & $24,7 \%$ \\
$\quad \leq 40$ & 21 & $75,3 \%$ \\
$>40$ & 64 & $32,9 \%$ \\
Masa Kerja & & $67,1 \%$ \\
$\quad \leq 5$ tahun & 28 & $7,1 \%$ \\
$\quad$ Desk Liputan & 57 & $92,9 \%$ \\
$\quad$ Kriminal & & 6 \\
$\quad$ Lainnya & 79 & \\
\hline
\end{tabular}

Pada tabel 1 dapat dilihat bahwa sebagian besar responden berusia lebih dari 35 tahun (80\%) dengan status pernikahan sudah menikah sebesar 55,3\%. Sebanyak 75 responden $(88,2 \%)$ jurnalis perempuan di Kota Palembang memiliki anak kurang dari 2 orang.

Dari tabel tersebut juga dapat dilihat bahwa sebagian besar responden $(75,3 \%)$ menghabiskan waktu lebih dari 40 jam seminggu untuk bekerja. Responden dengan masa kerja lebih dari 5 tahun sebanyak 57 orang $(67,1 \%)$. Hanya 2 responden $(2,4 \%)$ yang seharihari bertugas meliput informasi di desk kiriminal, sisanya sebagian besar di desk liputan selain bidang kriminal. Desk kriminal diketahui sebagai bidang liputan yang paling menantang khususnya untuk seorang jurnalis perempuan. 
Pada tabel 2 dapat dilihat bahwa hanya faktor risiko tuntutan pekerjaan yang dinyatakan berisiko oleh responden. Persentasenya sebesar $28,2 \%$. Sedangkan faktor risiko lainnya dinyatakan tidak berisiko oleh responden. Dari tabel 2 juga dapat dilihat bahwa responden yang berisiko stres kerja sebanyak 4 orang atau $4,7 \%$.

Tabel 2. Distribusi Frekuensi Faktor Risiko dan Stres Kerja

\begin{tabular}{lcc}
\hline \multicolumn{1}{c}{ Variabel } & N & $\%$ \\
\hline Tuntutan Pekerjaan & & \\
$\quad$ Berisiko & 24 & $28,2 \%$ \\
$\quad$ Tidak Berisiko & 61 & $71,8 \%$ \\
Kontrol Terhadap Pekerjaan & & $0 \%$ \\
$\quad$ Berisiko & 0 & $100 \%$ \\
$\quad$ Tidak Berisiko & 38 & $0 \%$ \\
Dukungan Sosial & & $100 \%$ \\
$\quad$ Berisiko & 0 & $0 \%$ \\
$\quad$ Tidak Berisiko & 85 & $100 \%$ \\
Hubungan Interpersonal & & \\
$\quad$ Berisiko & 0 & $0 \%$ \\
$\quad$ Tidak Berisiko & 85 & $100 \%$ \\
Peran & & \\
$\quad$ Berisiko & 0 & $0 \%$ \\
$\quad$ Tidak Berisiko & 85 & $100 \%$ \\
$\quad$ Perubahan Dalam Organisasi & & \\
$\quad$ Berisiko & 0 & $4,7 \%$ \\
$\quad$ Tidak Berisiko & 85 & $95,3 \%$ \\
Btres Kerja & & \\
$\quad$ Tidak berisiko & 4 & \\
\hline & 81 & \\
\hline
\end{tabular}

Menurut keempat responden faktor yang paling berisiko memicu stres adalah tuntutan pekerjaan. Faktor risiko lainnya seperti kontrol terhadap pekerjaan, dukungan sosial di tempat kerja, hubungan interpersonal, peran dan perubahan dalam organisasi dinyatakan tidak berisiko. Terkait dengan item pernyataan pada variabel tuntutan pekerjaan, keempat responden menyatakan tidak dapat beristirahat dengan cukup. Dua responden mengaku sering mendapat tuntutan pekerjaan dari berbagai kelompok kerja serta harus bekerja secara terus menerus. Dua responden lainnya terpaksa mengabaikan beberapa tugas karena terlalu banyak pekerjaan dan sering mendapatkan tekanan waktu yang tidak realistis.

\section{Analisis Bivariat}

Analisis bivariat antara demografi responden dengan faktor risiko tuntutan pekerjaan disajikan pada Tabel 3. Dari analisis bivariat menggunakan uji Fisher Exact Tes diketahui faktor risiko yang memberikan pengaruh signifikan terhadap keluhan stres kerja adalah tuntutan pekerjaan. Pada Tabel 3 dapat dilihat sebanyak 4 responden yang menyatakan 
tuntutan pekerjaan berisiko juga berisiko mengalami stres kerja. Sementara 20 orang responden yang juga menyatakan tuntutan pekerjaan berisiko, tidak berisiko mengalami stres kerja. Sebanyak 61 responden sisanya tidak menganggap tuntutan pekerjaan berisiko.

Nilai significancy keduanya sebesar 0,005 yang berarti ada hubungan antara tuntutan pekerjaan dengan terjadinya stres kerja pada jurnalis perempuan di Kota Palembang. Nilai Odds Ratio (OR) dengan tingkat kepercayaan 95\% kedua variabel ini adalah 0,833 yang berarti pada tingkat kepercayaan 95\% jurnalis perempuan di Kota Palembang dengan tuntutan pekerjaan berisiko memiliki risiko 0,833 kali lebih besar mengalami stres kerja dibanding jurnalis perempuan dengan tuntutan pekerjaan tidak berisiko.

Dari wawancara dan observasi psikolog diketahui bahwa keempat responden mengalami kecenderungan stres ringan. Stres tersebut dimoderasi oleh kepribadian masingmasing responden yang menyebabkan responden tidak dapat memanajemen tuntutan pekerjaan yang mereka dapatkan sehingga menimbulkan stres.

Responden A cenderung perfeksionis dan lebih suka bekerja sendiri. Responden A selalu ingin mendapatkan hasil yang sempurna dari apa yang dikerjakannya dan selalu mementingkan penilaian orang lain terhadap dirinya. Responden A juga tidak mudah percaya dengan orang lain, sehingga tugas-tugas yang semestinya bisa didelegasikan kepada bawahannya dalam hal ini wartawan, terkadang tidak dilakukannya.

Responden B mengaku selalu diliputi kecemasan karena kondisi suaminya yang divonis menderita kelainan jantung. Ia juga harus rutin menemani suaminya kontrol ke dokter dan rumah sakit. Kekhawatiran terhadap kondisi suaminya inilah yang memicu keluhan stres kerja dalam diri responden. Disatu sisi ia harus menjalankan tanggungjawab profesi dan disisi lain ia juga harus merawat suaminya tanpa ada keluarga yang bisa diandalkan karena keluarga mereka semuanya tinggal di luar kota.

Responden C memiliki kepribadian introvert, lebih suka memendam sendiri permasalahan yang dialaminya, baik yang terjadi di kantor maupun di lingkungan keluarganya. Responden C tidak pernah membagi masalah pribadinya kepada siapapun, karena sifatnya yang introvert tersebut. Hal inilah yang menurut psikolog dapat memicu keluhan terkait stres kerja pada responden $\mathrm{C}$.

Responden D memiliki emosi yang tidak stabil sehingga hal ini mengakibatkan rendahnya daya tahan responden $\mathrm{D}$ terhadap tekanan dan konflik yang terjadi di tempat kerja. 
Tabel 3. Hubungan faktor risiko dengan kejadian stres kerja

\begin{tabular}{|c|c|c|c|c|c|c|c|c|}
\hline \multirow[t]{2}{*}{ Variabel } & \multicolumn{2}{|c|}{ Berisiko } & \multicolumn{2}{|c|}{ Tidak Berisiko } & \multicolumn{2}{|c|}{ Total } & \multirow{2}{*}{$\begin{array}{c}\text { OR } \\
(95 \% \text { CI })\end{array}$} & \multirow[t]{2}{*}{ P Value } \\
\hline & $\mathbf{n}$ & $\%$ & $\mathbf{n}$ & $\%$ & $\mathbf{n}$ & $\%$ & & \\
\hline \multicolumn{9}{|l|}{ Usia } \\
\hline$\leq 35$ tahun & 0 & 0 & 17 & 100 & 17 & 100 & 1,063 & 0,579 \\
\hline$>35$ tahun & 4 & 5,9 & 64 & 94,1 & 68 & 100 & $(1,001-1,128)$ & \\
\hline \multicolumn{9}{|l|}{ Status } \\
\hline \multicolumn{9}{|l|}{ Pernikahan } \\
\hline Belum menikah & 1 & 2,6 & 37 & 37,4 & 38 & 100 & 1,250 & 1,000 \\
\hline Menikah & 3 & 6,4 & 44 & 93,6 & 47 & 100 & $(0,168-9,314)$ & \\
\hline \multicolumn{9}{|l|}{ Jumlah Anak } \\
\hline$\leq 2$ orang & 3 & 4 & 72 & 96 & 75 & 100 & 0,375 & 0,400 \\
\hline$>2$ orang & 1 & 10 & 9 & 90 & 10 & 100 & $(0,035-3,999)$ & \\
\hline \multicolumn{9}{|l|}{ Lama Kerja } \\
\hline$\leq 40 \mathrm{jam} / \mathrm{minggu}$ & 1 & 4,8 & 20 & 95,2 & 21 & 100 & 1,067 & 0,568 \\
\hline$>40 \mathrm{jam} / \mathrm{minggu}$ & 3 & 4,7 & 61 & 95,3 & 64 & 100 & $(1,001-1,136)$ & \\
\hline \multicolumn{9}{|l|}{ Masa Kerja } \\
\hline$\leq 5$ tahun & 0 & 0 & 28 & 100 & 28 & 100 & 1,075 & 0,297 \\
\hline$>5$ tahun & 4 & 7 & 53 & 93 & 57 & 100 & $(1,001-1,155)$ & \\
\hline \multicolumn{9}{|l|}{ Desk Liputan } \\
\hline Kriminal & 0 & 0 & 6 & 100 & 6 & 100 & 5,067 & 0,258 \\
\hline Lainnya & 4 & 5,1 & 75 & 94,9 & 79 & 100 & $(0,443-57,978)$ & \\
\hline \multicolumn{9}{|l|}{ Tuntutan } \\
\hline \multicolumn{9}{|l|}{ Pekerjaan } \\
\hline Tidak Berisiko & 0 & 0 & 61 & 100 & 61 & 100 & 0,833 & 0,005 \\
\hline Berisiko & 4 & 16,7 & 20 & 83,3 & 24 & 100 & $(0,697-0,997)$ & \\
\hline
\end{tabular}

\section{PEMBAHASAN}

Hasil analisis hubungan antara tuntutan pekerjaan dengan stres kerja didapatkan $p$ value $=0,005(95 \%$ CI $0,697-0,997)$ dengan $\mathrm{OR}=0,833$. Hal ini menunjukkan ada hubungan bermakna antara tuntutan pekerjaan dengan stres kerja. Pada penelitian ini, dari jawaban pertanyaan tentang tuntutan pekerjaan, keempat responden dikategorikan ke dalam responden yang berisiko mengalami kecenderungan stres ringan menurut psikolog.

Dari item pernyataan tentang tuntutan pekerjaan, keempat responden menjawab bahwa mereka tidak dapat beristirahat dengan cukup dan dihadapkan pada tekanan waktu yang tidak realistis. Ini terjadi ketika mereka kesulitan menemui atau menghubungi narasumber. Mereka harus terus berusaha agar mendapatkan konfirmasi dari narasumber yang bersangkutan karena bila tidak berhasil mengkonfirmasi maka berita yang mereka buat tidak akan diterbitkan.

Selain itu bila jumlah berita yang ditargetkan belum mereka capai, mereka harus bisa mencari peluang berita lain untuk memenuhi target. Sementara mereka setiap harinya memiliki deadline yang harus dipatuhi demi kelancaran proses produksi. Mereka juga dituntut untuk mendapatkan berita yang menarik dan eksklusif ditengah ketatnya persaingan media cetak saat ini. 
Transformasi dari media konvensisonal ke media digital juga menuntut para jurnalis untuk meningkatkan skill agar dapat beradaptasi dengan perkembangan media digital saat ini. Upaya meningkatkan keterampilan dalam diri jurnalis cukup menyita waktu dan menguras otak karena mereka harus meluangkan waktu untuk kembali belajar, sementara peran ganda mereka sebagai istri dan ibu juga tetap harus mereka jalankan ketika di rumah.

Dari hasil wawancara dan observasi langsung oleh psikolog dijelaskan bahwa faktor pencetus utama stres pada responden adalah tipe kepribadiannya. Daya tahan yang kurang baik dalam menghadapi tekanan dan konflik kerja menjadi faktor utama penyebab terjadinya kecenderungan stres ringan menurut psikolog.

Jurnalis memiliki pola kerja yang tidak mengenal waktu. Mereka harus siap meliput kapanpun ada peristiwa penting terjadi. Hal tersebut membuat waktu istirahat mereka berkurang, terlebih lagi mereka harus memenuhi tenggat waktu pengumpulan berita yang diberikan perusahaan(Munandar AS, 2001).

Profesi sebagai jurnalis yang selalu dihadapkan dengan deadline telah mendorong akumulasi stres yang bisa menimbulkan penyakit syaraf. Selain secara fisik, wartawan juga rentan mengalami gangguan psikologis. Seringnya menyaksikan kejadian-kejadian traumatis seperti kerusuhan, korban pembunuhan atau bencana alam dapat menimbulkan pengaruh psikologis dalam diri wartawan(Dart Centre, 2006).

Beban kerja berlebih kuantitatif dan kualitatif serta beban kerja terlalu sedikit merupakan pembangkit stres. Beban berlebih secara fisikal ataupun mental yaitu harus melakukan banyak hal yang merupakan sumber stress pekerjaan(Ashar Sunyoto Munandar, 2001). Beban kerja juga merupakan penyebab stres yang signifikan yang memunculkan jenis reaksi psikologi yang merusak dan menumbuhkan gejala burnout(Ashforth and Humphrey, 1993).

Teori menurut Ashar Teori Hureel dan Aristequeta(Levy, Barry S. Wegman, David H. Baron, Sherry L. Sokas, 2006) menjelaskan bahwa stres kerja memiliki beberapa faktor yang menjadi penyebabnya, salah satunya faktor individu yang berupa umur, sifat atau kepribadian dan status pernikahan. Selain itu juga ada faktor job stressors yang berupa beban kerja. Ini berarti beban kerja yang erat kaitannya dengan tuntutan pekerjaan memang memiliki pengaruh terhadap stres kerja. Namun demikian ada juga faktor lain yaitu sifat atau kepribadian.

Hasil penelitian ini sejalan dengan hasil penelitian pada perawat di IGD RSUD Cianjur yaitu ada hubungan antara beban kerja dengan stres kerja (p-value 0,048)(Kasmarani, 2012). Penelitian stres kerja terhadap Polisi Wanita di Polresta Palembang juga menunjukkan ada 
hubungan antara beban kerja dengan stres kerja ( $p$-value 0,022 OR 0,870;95\% CI 0,742 1,019)(Marlyna Leni, 2017). Hasil penelitian ini jugasejalan dengan penelitian pada pekerja wanita di PT X di Jawa Barat dimana ada hubungan antara beban kerja dengan stres kerja ( $p$ value 0,040)(Muslimin, 2019).

Stres kerja dapat menimbulkan dampak kerugian yang besar bila tidak dimanage dengan baik, karena stres kerja dapat menimbulkan penyakit diantaranya Musculoskeletal Disorders. Manajemen stres mencakup enam elemen penting dalam mengendalikan stres kerja atau work related stress. Jika enam elemen tersebut tidak ditangani dengan baik maka akan berdampak terhadap kesehatan pekerja, kesejahteraaan pekerja, produktivitas kerja, kecelakaan kerja, kenyamanan bekerja, hubungan kerja dan dampak lainnya(Health Safety Executive (HSE), 2001).

NIOSH menyatakan bahwa ada dua cara yang dapat dilakukan untuk mengatasi stres dalam pekerjaan. Pertama, dengan manajemen stres dan Employee Assistance Program (AEP), untuk meningkatkan kemampuan pekerja dalam menghadapi situasi kerja yang sulit. Program manajemen stres mengajarkan pekerja tentang sifat stres, sumber stres, efek stres pada kesehatan dan ketrampilan pribadi untuk mengurangi stres, misalnya manajemen waktu atau latihan relaksasi. EAP memberikan konseling individual kepada pekerja untuk menceritakan masalah kerjanya dan masalah pribadinya(National Institute for Occupational, 1999).

Kedua, dengan perubahan organisasi (Organizational Change). Cara ini dilakukan dengan membawa konsultan untuk merekomendasikan bagaimana cara memperbaiki kondisi kerja. Pendekatan ini dipilih sebagai cara yang langsung dapat mengurangi stres di tempat kerja. Keuntungan dari pendekatan ini adalah cara ini berhubungan langsung dengan akar penyebab stres di tempat kerja, sehingga dapat mengatasi stres dengan cepat. Namun pimpinan kerja terkadang merasa tidak nyaman dengan pendekatan ini, karena dapat menimbulkan perubahan rutinitas kerja, jadwal produksi dan perubahan dalam struktur organisasi.

\section{KESIMPULAN}

Berdasarkan hasil penelitian dapat disimpulkan bahwa kejadian stres kerja pada jurnalis perempuan di Kota Palembang sebesar 4,7\% dan faktor risiko yang paling berpengaruh adalah tuntutan pekerjaan ( $\mathrm{p}$ value $=0,005$ (95\% CI 0,697-0,997)). Hasil wawancara dan observasi langsung oleh psikolog menyatakan bahwa faktor yang memicu stres kerja adalah tipe kepribadian. Sedangkan usia, status pernikahan, jumlah anak, lama kerja, masa kerja, 
desk liputan, kontrol terhadap pekerjaan, dukungan sosial, hubungan interpersonal, peran dan perubahan dalam organisasi tidak memiliki pengaruh terhadap stres kerja.

Evaluasi terhadap tuntutan pekerjaan perlu dilakukan oleh pimpinan atau atasan langsung dari jurnalis perempuan agar dapat meminimalisir stres kerja. Kerjasama dengan psikolog untuk sosialisasi manajemen stres juga dapat dilakukan sebagai langkah pencegahan terjadinya stres kerja.

\section{DAFTAR PUSTAKA}

Ashar Sunyoto Munandar (2001) Psikologi Industri dan Organisasi. Jakarta: Universitas Indonesia (UI-Press).

Ashforth, B. E. and Humphrey, R. H. (1993) 'Emotional Roles : the Influence', The Academy of Management Review.

Balhara, Y. S., Verma, R. and Gupta, C. (2012) 'Gender differences in stress response: Role of developmental and biological determinants', Industrial Psychiatry Journal. doi: 10.4103/0972-6748.98407.

Dart Centre (2006) Meliput Trauma: Panduan Dart Centre Untuk Para Wartawan, Redaktur, Dan Manajer, Dart Centre For Journalist \& Trauma. Available at: https://dartcenter.org/sites/default/files/bahasa_tnj.pdf (Accessed: 10 September 2020).

EU-OSHA (2002) How to tackle psychosocial issues and reduce work-related stress, Luxembourg: Office for Official Publications of the European Communities.

Health and Safety Executve, HSE and Health and Safety Executve (2017) 'Work-related Stress, Depression or Anxiety Statistics in Great Britain 2017', Health and Safety Executive Report.

Health Safety Executive (HSE) (2001) A Critical Review of Psychosocial Hazard Measure. Sudbury: Suffolk.

HSE (2019) 'Work-related stress, anxiety or depression statistics in Great Britain , 2019', Annual Statistics.

Kasmarani, M. K. (2012) 'Pengaruh Beban Bekerja Perawat Pada Instalasi Di Darurat Gawat RSUD I G D', Jurnal Kesehatan Masyarakat (e-Journal).

Levy, Barry S. Wegman, David H. Baron, Sherry L. Sokas, R. K. (2006) 'Occupational and environmental health: recognizing and preventing disease and injury.Levy.1pdf', in Occupational and environmental health: recognizing and preventing disease and injury.

Luviana (2012) Jejak jurnalis perempuan: pemetaan kondisi kerja jurnalis perempuan di Indonesia. Jakarta: Aliansi Jurnalis Independen (AJI) Indonesia.

Marlyna Leni (2017) Analisis Faktor Risiko Stres Kerja Pada Jurnalis Perempuan di Kota Palembang. Universitas Sriwijaya.

Muala, I. Al (2017) 'Job Stress in Journalism: Interaction between Organisational Support and Job Demands-Resources Model', Journal of Management and Sustainability, 7(4), p. 150. doi: 10.5539/jms.v7n4p150.

Munandar AS (2001) Psikologi Industri dan Organisasi. UI Press.

Muslimin (2019) Faktor-Faktor Yang Berhubungan Dengan Stres Kerja Pada Pekerja Wanita, Jurnal Kesehatan. Available at: http://jurnal.stikescirebon.ac.id/index.php/kesehatan/article/view/13/13 (Accessed: 10 September 2020).

National Institute for Occupational (1999) STRESS...at work.,Safety And Health. 
NIOSH (2001) Women's Safety and Health Issues At Work. Available at: https://www.cdc.gov/niosh/docs/2001-123/default.html (Accessed: 18 January 2020).

Parent-Thirion, A. et al. (2007) Fourth European Working Conditions Survey, Context. doi: www. eurofound.eu.int/ewco/surveys/EWCS2005/index.htm.

Pratama (2012) Studi Bahaya Psikososial Terhadap Stres Kerja Pada Pemadam Kebakaran Di Depok Pada 2012. Universitas Indonesia.

Soeroso (2008) Sosiologi 2. Jakarta: Quadra.

Wang, M. and Jiang, Z. (2016) 'Greater work-related stress among Chinese media workers in the context of media transformation: Specific stressors and coping strategie', International Journal of Communication, 10, pp. 6103-6125. 